\title{
Regnum und gens
}

Als Jesus gekreuzigt wurde, stand nach übereinstimmender Nachricht der Evangelisten auf einem Schild über ihm der Titel rex Iudaeorum. ${ }^{1}$ Es waren die Römer, die auf diese Weise seine causa, den Grund seiner Verurteilung, öffentlich machten. Die römischen Soldaten hatten ihn als ,König der Juden ' verspottet; was die Juden in ihm sahen, wird in den Evangelien widersprüchlich dargestellt. Er ist übrigens der einzige, der in der Bibel diesen Titel trägt, sonst ist immer von einem König von Juda oder einem König von Israel die Rede. Von einem basileus Ioudaiōn spricht allerdings, wenn auch selten, Flavius Josephus für die Zeit des Herodes. ${ }^{2}$ Ethnisch bezeichnete Könige verschwanden in der Folge vom römischen Territorium.

Das Verhältnis des römischen Reiches zur Ethnizität war widersprüchlich und distanziert. Patrick Geary hat gezeigt, dass in der lateinischen Staatssprache populus einen konstitutionellen, gens einen ethnischen Volksbegriff verkörpert. ${ }^{3}$ Republikanischer Magistrat wie kaiserliche Herrschaft beriefen sich auf den römischen Populus, das zumindest in der politischen Theorie entscheidungsbefugte Kollektiv: senatus populusque Romanus. Daneben gab es zwar die Vorstellung von einer gens Romana und einer spezifischen römischen Identität zum Unterschied von anderen Völkern. Doch schon Livius hatte die römischen Ursprünge als Entstehung eines römischen Populus aus mehreren Gentes geschildert und damit kanonisiert. ${ }^{4}$ „Indem niemand wegen seiner Herkunft abgelehnt wurde, sofern er nur tüchtig war, wuchs das Römische Reich“, betonte er. ${ }^{5}$ Das Bürgerrecht konnte deshalb von der Herkunft unabhängig gehandhabt werden; mit der Lex Plautia Papiria wurde es allen Bundesgenossen übertragen, mit der Constitutio Antoniniana allen freien Bürgern des Reiches. ${ }^{6}$ Die Verleihung des ius honorum und damit die Öffnung des Senates für Bürger aus den Provinzen (zunächst aus Gallien) durch Claudius verhinderte die Abschließung der römischen Elite, führte aber zugleich dazu, dass die römische Identität, wie Andrea Giardina festgestellt hat, „unvollendet“ und damit offen für neue Aneignungen blieb. ${ }^{7}$ Daneben hielten sich städtische, aber auch provinzielle und regionale Identitäten, die immer wieder (re-)ethnisiert werden konnten, aber keine Grundlage für dauerhafte Sonderherrschaft boten. ${ }^{8}$ Aus christlicher Sicht hatte sich das Imperium Romanum deshalb so ausgebreitet, damit

\footnotetext{
* Diese Arbeit entstand im Zusammenhang des Projektes, das durch die Verleihung des Wittgenstein-Preises des Fonds zur Förderung der wissenschaftlichen Forschung (FWF) ermöglicht wurde und am Institut für Mittelalterforschung der Österreichischen Akademie der Wissenschaften sowie am Institut für Österreichische Geschichtsforschung an der Universität Wien durchgeführt wird.

${ }^{1}$ Mt 27, 37 (Iesus rex Iudaeorum), Mk 15, 26 und Lk 23, 39 (rex Iudaeorum), Io 19, 19 (Iesus Nazarenus rex Iudaeorum).

${ }^{2}$ Flavius Josephus, Antiquitates Iudaicae 15, 409 (für Herodes); Flavius Josephus, Bellum Iudaicum 1, 14, 4 (Antonius will Antipater zum König der Juden machen).

${ }^{3}$ Siehe dazu Patrick J. Geary, Europäische Völker im frühen Mittelalter. Zur Legende vom Werden der Nationen (Frankfurt am Main 2001).

${ }^{4}$ Livius, Praefatio und Buch 1. Die ,politische Origo‘ der Römer beschreibt besonders Livius 1, 8: Rebus divinis rite perpetratis vocataque ad concilium multitudine quae coalescere in populi unius corpus nulla re praeterquam legibus poterat, iura dedit. Siehe auch Alexander Demandt, Die Spätantike. Römische Geschichte von Diocletian bis Justinian 284565 n. Chr. (München $\left.{ }^{2} 2007\right) 366$.

${ }^{5}$ Livius 4, 3, 13: Dum nullum fastiditur genus, in quo eniteret virtus, crevit imperium Romanum.

${ }^{6}$ Hartmut Wolff, Die constitutio Antoniniana und Papyrus Gissensis 40 I, 2 Bde. (Köln 1976).

7 Andrea Giardina, L’Italia Romana - storie di una identità incompiuta (Roma/Bari 1997).

${ }^{8} \mathrm{Im}$ 2. Jahrhundert etwa konnten die Provinzen auf griechisch als ethnē bezeichnet werden, siehe Henry G. Liddell/Robert Scott, A Greek-English Lexicon (Oxford 1968) 480; siehe dazu künftig Roland Steinacher, Rome and its created northeners: Germani or Celts, Goths or Scyths, Suevi and Alamanni?, in: Friends, Enemies, Neighbors. Romans and Alamanni in Late Antique Germany, ed. Michael Kulikowski/Philipp von Rummel (in Vorbereitung). In der Spätantike wurde in
} 
alle Gentes leichter Kontakt zum Christentum erhalten konnten. ${ }^{9}$ Die ethnische Offenheit Roms konnte seit Paulus zum impliziten Vorbild für den universalen Anspruch des Christentums werden.

Doch betrachteten die Römer selbstverständlich ihre barbarischen Nachbarn als Gentes. Schon Aristoteles hatte die Identitätsmuster der klassischen Zivilisation von ihren Nachbarn unterschieden: die Griechen leben in der polis, während die Barbaren in ethne gegliedert sind. ${ }^{10}$ Das erleichterte Wahrnehmung wie Kontrolle der Verhältnisse im Barbaricum, auch wo es nicht ganz zutraf. Längerfristig führte die Einteilung der Barbaren in Gentes vermutlich auch dazu, dass sich deren ethnische Strukturen verfestigen konnten. Dabei konnte auch die ethnische Gliederung der Auxiliar-Einheiten mitspielen. In der Historiographie wurde ,barbarisches‘ Handeln deshalb vor allem Völkern zugeschrieben. Flavius Josephus etwa beschrieb so die Verhältnisse im alten Orient. Er gebraucht für fremde Völker meist einen ethnischen oder ethnisierten Königstitel: der Pharao ist der basileus der Ägypter (und nicht Ägyptens), Nebukadnezar derjenige der Babylonier und Kyros der Perser; zeitgenössisch treten etwa Könige der Parther, Adiabener oder Kappadokier auf. ${ }^{11}$ Davon abgehoben werden die Römer, die vom Kaisar, etwa Klaudios, regiert werden. ${ }^{12}$ Dem Alten Testament lag eine ähnliche Unterscheidung in das Volk Israel (meist am genannt) und den fremden Völkern (goyim) zu Grunde. Freilich unterscheidet die hebräische Terminologie der Ethnizität nicht durchgehend zwischen Eigenund Fremdbezeichnung. ${ }^{13}$ Die Vulgata gibt den ausländischen Herrschern in der Regel ethnische Königstitel. ${ }^{14}$ Im römischen Kaisertitel fehlte jedenfalls der Bezug auf Rom, nur die Triumphnamen wie Gothicus, Alamannicus oder Persicus hatten einen ethnischen Bezug; aber sie beschrieben gerade nicht das Staatsvolk, sondern besiegte Gentes. ${ }^{15}$

\section{AUSSERRÖMISCHE GENTES UND VÖLKERWANDERUNGSZEITLICHE REGNA}

Könige mit ,gentiler` Herrschaftsbezeichnung konnten sich auf römischem Boden erst wieder ab dem 5. Jahrhundert durchsetzen. Der Bezug vom Regnum zur Gens, zwischen ethnischer Identität und politischer Herrschaft in ihren Reichen ist in der Forschung lange Zeit ganz unproblematisch gesehen worden: Die Germanen hatten die ethnische Begründung ihrer Königsherrschaft eben mitgebracht. Doch dieser Kontinuitätsstrang ist bei näherem Zusehen äußerst problematisch.. ${ }^{16}$ Dass die Goten,

Gallien von römischen Intellektuellen (etwa Sidonius Apollinaris) an alte gallische Stammesnamen angeknüpft; zum Kontext: Ralph Whitney Mathisen, Roman Aristocrats in Barbarian Gaul. Strategies for Survival in an Age of Transition (Austin 1993). Siehe auch Demandt, Spätantike 368-373.

9 Siehe z. B. Leo I. magnus, Tractatus septem et nonaginta 82 (ed. Antoine Chavasse, CC SL 138/138A, Turnhout 1973); Prosper Tiro, De vocatione omnium gentium, PL 51, 648a-722b.

10 Aristoteles, Politika 1261a; 1276a; vgl. Walter Pohl, Varietà etnica nell’Europa meticcia dell'alto Medioevo, in: Europa in costruzione. La forza delle identità, la ricerca di unità (secoli IX-XIII), ed. Giorgio Cracco/Jacques Le Goff/Hagen Keller/Gerolamo Ortalli (Bologna 2006) 55-72.

11 Flavius Josephus, Antiquitates 1, 163; 20, 231; 20, 233; 20, 54; 20, 81; 16, 11. Es gibt aber auch den basileus tēs Arabias (ebd. 16, 220).

12 Flavius Josephus, Antiquitates 20, 222.

13 Otto Bächli, Israel und die Völker. Eine Studie zum Deuteronomium (Zürich/Stuttgart 1962); Christiana van Houten, The Alien in Israelite Law (Sheffield 1991); Josef Schreiner/Rainer Kampling, Der Nächste - der Fremde - der Feind (Neue Echter Bibel: Themen 3, Würzburg 2000); Ethnicity and the Bible, ed. Mark G. Brett (Boston/Leiden 2002). Siehe auch Geary, Europäische Völker Kapitel 2, und Jeremy DuQuesnay Adams, The Populus of Augustine and Jerome: A Study in the Patristic Sense of Community (New Haven 1971).

14 Z. B. rex Persarum I Esr 1, 1, rex Assyriorum II Par 32, 21 etc. Der Pharao ist allerdings der rex Aegypti, z. B. Ex 2, 23 et passim. Siehe Geary, Europäische Völker Kapitel 2.

15 Zum spätantiken Kaisertitel Gerhard Rösch, Onoma Basileias. Studien zum offiziellen Gebrauch der Kaisertitel in spätantiker und frühbyzantinischer Zeit (Byzantina Vindobonensia 10, Wien 1978); Alexander Demandt, Die Spätantike. Römische Geschichte von Diocletian bis Justinian 284-565 n. Chr. (München ${ }^{2} 2007$ ) 260f.

16 Einen systematischen Vergleich bietet der Band Regna et Gentes. The Relationship between Late Antique and Early Medieval Peoples and Kingdoms in the Transformation of the Roman World, ed. Hans-Werner Goetz/Jörg Jarnut/Walter Pohl (The Transformation of the Roman World 13, Leiden/Boston/Köln 2003); siehe darin vor allem Hans-Werner Goetz, Introduction (1-13) und die auch wesentlich von ihm verfasste Conclusion, 597-629. Siehe auch Karl Ferdinand Werner, Die ,Franken`. Staat oder Volk?, in: Die Franken und die Alemannen bis zur „Schlacht bei Zülpich“ (496/97), ed. Dieter Geuenich (RGA Erg. Bd. 19, Berlin/New York 1998) 95-101; Karl Ferdinand Werner, Völker und Regna, in: Beiträge zur mittelalterlichen Reichs- und Nationsbildung in Deutschland und Frankreich, ed. Carlrichard Brühl/Bernd 
Langobarden oder Franken des 6. Jahrhunderts nicht einfach identisch mit den gleich oder ähnlich benannten Völkern früherer Jahrhunderte waren, ist in der Forschung seit Reinhard Wenskus unter dem Stichwort ,Ethnogenese allmählich rezipiert worden. ${ }^{17}$ Wenskus vertrat die These, dass nicht ganze Völker, wohl aber Kerngruppen mit ihrer jeweiligen Tradition und Verfassung gewandert seien. Mit den Germanen habe sich auf dem Boden des Imperiums eine andere Denkform durchgesetzt, der „Gentilismus“. ${ }^{18}$

Doch diese Vorstellung von der Durchsetzung einer außerrömischen Tradition der Ethnizität ist nicht unproblematisch. Zwar ist evident, dass es tatsächlich zahlreiche kleinere und größere Migrationen aus dem Barbaricum ins Römische Reich gegeben hat. Viele der Völkernamen, die später Reiche auf römischem Boden bezeichneten, waren zudem in derselben oder ähnlicher Form schon in der Germania bezeugt: Gutonen/Goten, Langobarden, Sueben, Burgundionen/Burgunder, Vandilier/Vandalen und andere. Manche haben zudem auffällige Parallelen im skandinavischen Raum. Bei vielen von ihnen sind aber Identitätsbrüche und Neubildungen belegbar, wie bei den Goten, Sueben oder Vandalen. ${ }^{19}$ Andere verschwinden für viele Jahrhunderte aus den Quellen, um an anderer Stelle wieder aufzutauchen, wie die Langobarden. ${ }^{20}$ Und gegen die alte Vorstellung von einer Herkunft der Goten, Burgunder und Langobarden aus Skandinavien sind gewichtige Bedenken geäußert worden, sodass sie heute im Wesentlichen aufgegeben ist. ${ }^{21}$ Schwierig ist auch der Nachweis tatsächlicher Kontinuität von Traditionen und Verfassungen. Die Origines gentium der Goten und Langobarden, früher als entscheidende Zeugnisse uralter Traditionen angesehen, enthalten zwar vorethnographische Daten, gehen aber wohl kaum vor die Völkerwanderungszeit zurück. ${ }^{22}$ Das Wenskus'sche Modell des Traditionskerns ist also nur ein möglicher Erklärungsansatz für Namenskontinuität. Im Wechselspiel zwischen Fremd- und Selbstbezeichnung ist es ebenso vorstellbar, dass alte, prestigeträchtige Namen wieder aufgegriffen wurden, ohne dass ein ,Kern' sie weitergetragen hatte. In der eurasischen Steppe des Frühmittelalters ist das vielfach belegbar. Nach dem byzantinischen Historiker Theophylaktus Simocatta zum Beispiel waren die Awaren zunächst irrtümlich von anderen so genannt worden; sie

Schneidmüller (Historische Zeitschrift, Beiheft N.F. 24, München 1997) 15-44; Matthias Becher, Rex, Dux und Gens: Untersuchungen zur Entstehung des sächsischen Herzogtums im 9. und 10. Jahrhundert (Husum 1996); Leges - Gentes Regna. Zur Rolle von germanischen Rechtsgewohnheiten und lateinischer Schrifttradition bei der Ausbildung der frühmittelalterlichen Rechtskultur, ed. Gerhard Dilcher/Eva-Maria Distler (Berlin 2006).

17 Reinhard Wenskus, Stammesbildung und Verfassung. Das Werden der frühmittelalterlichen gentes (Köln/Wien 1961, ${ }^{2}$ 1977); Herwig Wolfram, Die Goten. Von den Anfängen bis zur Mitte des sechsten Jahrhunderts (München ${ }^{3} 1990$,

${ }^{4}$ 2001); Forschungsüberblick: Walter Pohl, Tradition, Ethnogenese und literarische Gestaltung: eine Zwischenbilanz, in: Ethnogenese und Überlieferung. Angewandte Methoden der Frühmittelalterforschung, ed. Karl Brunner/Brigitte Merta (VIÖG 31, Wien 1994) 9-26.

${ }^{18}$ Wenskus, Stammesbildung 2: „Der ,Gentilismus‘ der landnehmenden Stämme war als Denkform politisch stärker als das römische Reichsbewußtsein der Provinzialen. “ Siehe dazu Walter Pohl, Gentilismus, in: RGA 2. Aufl. 11 (Berlin/New York 1998) 91-101.

19 Walter Pohl, Die Völkerwanderung. Eroberung und Integration (Stuttgart/Berlin/Köln 2002); Wolf Liebeschuetz, Gens into regnum: the Vandals, in: Regna et Gentes. The Relationship between Late Antique and Early Medieval Peoples and Kingdoms in the Transformation of the Roman World, ed. Hans-Werner Goetz/Jörg Jarnut/Walter Pohl (The Transformation of the Roman World 13, Leiden/Boston/Köln 2003) 55-84, bes. 58-62; Ian N. Wood, The Kingdom of the Gibichungs, in: ebd. 243-270; Hans-Werner Goetz, Gens, kings and kingdoms: the Franks, in: ebd. 307-344; Herwig Wolfram, Auf der Suche nach den Ursprüngen, in: ders., Gotische Studien. Volk und Herrschaft im frühen Mittelalter (München 2005) 225-240, 233f.

${ }^{20}$ Walter Pohl, Migration und Ethnogenese der Langobarden aus Sicht der Schriftquellen, in: Kulturwandel in Mitteleuropa. Langobarden - Awaren - Slawen, ed. Jan Bemmann/Michael Schmauder (Römisch-germanische Kommission, Kolloquien zur Vor- und Frühgeschichte 11, Bonn 2008) 1-12.

${ }^{21}$ Rolf Hachmann, Die Goten und Skandinavien (Berlin 1970); Volker Bierbrauer, Die Goten vom 1.-7. Jahrhundert n. Chr.: Siedelgebiete und Wanderbewegungen aufgrund archäologischer Quellen (Peregrinatio Gotica 3, Oslo 1992) 9-43.

${ }^{22}$ Wie weit sich in dieser Hinsicht der Forschungsstand geändert hat, zeigt sich am Vergleich von Otto Höfler, Abstammungstraditionen, in: RGA 2. Aufl. 1 (Berlin/New York 1973) 18-29; und Herwig Wolfram/Walter Pohl/Ian N. Wood u.a., Origo gentis, in: RGA 2. Aufl. 22 (Berlin/New York 2003) 174-210. Siehe auch Walter Pohl, Probleme einer Sinngeschichte ethnischer Gemeinschaften - Identität und Tradition, in: Leges - Gentes - Regna. Zur Rolle von germanischen Rechtsgewohnheiten und lateinischer Schrifttradition bei der Ausbildung der frühmittelalterlichen Rechtskultur, ed. Gerhard Dilcher/Eva-Maria Distler (Berlin 2006) 51-68. 
selbst übernahmen dann diese Fremdbezeichnung, weil sie bei den Feinden Schrecken erregte. ${ }^{23}$ Es ist nicht unwahrscheinlich, dass auch ,Franken ' und ,Alemannen` aus römischen Pauschalbezeichnungen für die unübersichtlich gewordene ethnische Landschaft des 3. Jahrhunderts in der Germania entstanden. ${ }^{24}$ Ungebrochene ethnische Kontinuität als Grundlage der neuen Regna ist also nicht vorauszusetzen; wie sich die barbarischen Identitäten bildeten, die schließlich auf römischem Boden herrschaftswirksam wurden, ist in einzelnen Fällen offenbar recht unterschiedlich gewesen. Deutlich wird jedoch, dass die Gentes der Völkerwanderungszeit auf außerrömische Identitätsressourcen zurückgriffen. Es gibt keinen Namen eines barbarischen Königreiches auf römischem Boden, der nicht schon zuvor außerhalb der Reichsgrenzen bezeugt ist.

Noch schwieriger ist das Regnum direkt aus ,germanischen` Vorformen abzuleiten. ${ }^{25}$ Das alte Modell eines ,germanischen Heerkönigtums` beruht auf der zutreffenden Beobachtung, dass erfolgreiche Reichsgründungen auf römischem Boden ein starkes und loyales Heer voraussetzten. ${ }^{26}$ Aber der Aufbau und vor allem die Konsolidierung eines solchen Heeres setzten wiederum die römische Infrastruktur voraus; daran scheiterten letztlich auch Arminius und Marbod. Wie Herwig Wolfram gezeigt hat, hing das germanische Königtum seit Caesar eng mit der römischen Ordnungspolitik jenseits der Reichsgrenzen zusammen. ${ }^{27}$ Ariovist, Arminius und Marbod erreichten eine beträchtliche Machtkonzentration, konnten sie aber nicht lange behaupten. Als sich die Herrschaft Roms an Rhein und Donau konsolidiert hatte, verschwand das großräumige Königtum aus der Germania. Die reges vom fortgeschrittenen 1. bis zum 5. Jahrhundert waren Anführer recht kleiner Barbarengruppen, wie etwa die zahlreichen Alemannenkönige, die Julian 357 bei Argentoratum gegenüberstanden. ${ }^{28}$ An diesem Beispiel lässt sich auch zeigen, dass es sich um keinen formellen ,Stammesverband ${ }^{29}{ }^{29}$ handelte, denn die Bündnisse zwischen diesen Reges mussten erst ausgehandelt werden. Auch bei den Franken gab es vor Chlodwig eine Vielzahl von reges. Schon Gregor von Tours hatte deshalb Schwierigkeiten, den Ursprung des fränkischen Königtums zu ergründen; er meinte, die Franken hätten nur duces gehabt. ${ }^{30}$ Chlodwig hatte also kein ,germanisches“ Vorbild für sein überregionales Regnum; er musste es gegen große Widerstände aus den alten Führungsgruppen und der eigenen Familie, sozusagen im Kampf gegen den eigenen ,Traditionskern`, gewaltsam durchsetzen. ${ }^{31}$ Die Sugambrer, an die Remigius von

${ }^{23}$ Theophylactus Simocatta VII, 7 (übers. Peter Schreiner, Bibliothek der griechischen Literatur 20, Stuttgart 1985) 186; Hans-Werner Haussig, Die Geschichte Zentralasiens und der Seidenstraße in vorislamischer Zeit (Darmstadt 1983); Walter Pohl, Die Awaren. Ein Steppenvolk in Mitteleuropa, 567-822 n. Chr. (München $\left.{ }^{2} 2002\right)$ 27-37.

${ }^{24}$ Hans Jänichen, Alemannen, in: RGA 2. Aufl. 1 (Berlin/New York 1973) 138f.; Herwig Wolfram, Das Reich und die Germanen. Zwischen Antike und Mittelalter (Berlin $\left.{ }^{2} 1992\right)$ 82; Walter Pohl, Die Germanen (Enzyklopädie deutscher Geschichte 57, München 22004) 29-35; Goetz, Gens, kings and kingdoms 308f.

25 Grundlegend für die Lehre von den germanischen Wurzeln des mittelalterlichen Königtums: Otto Höfler, Das germanische Kontinuitätsproblem, in: Historische Zeitschrift 157 (1938) 1-26.

${ }^{26}$ Grundlegend: Walter Schlesinger, Das Heerkönigtum, in: Vorträge und Forschungen 3 (Sigmaringen 1956) 105-142.

27 Siehe den Beitrag von Herwig Wolfram in diesem Band, sowie ders., Rom und das frühe Königtum nördlich der Alpen, in: ders., Gotische Studien. Volk und Herrschaft im frühen Mittelalter (München 2005) 15-65; Stefanie Dick, Zu den Grundlagen des sogenannten germanischen Königtums, in: Akkulturation - Probleme einer germanisch-romanischen Kultursynthese in Spätantike und frühem Mittelalter, ed. Dieter Hägermann/Wolfgang Haubrichs/Jörg Jarnut (RGA Erg. Bd. 41, Berlin/New York 2004) 510-527; dies., Der Mythos vom ,germanischen` Königtum. Studien zur Herrschaftsorganisation bei den germanischsprachigen Barbaren bis zum Beginn der Völkerwanderungszeit (RGA Erg. Bd. 60, Berlin/New York 2008).

${ }^{28}$ Ammianus Marcellinus, Rerum gestarum libri XVI, 12 (ed. Wolfgang Seyfarth, Rerum gestarum libri XXXI, Leipzig 1999) 89. Zur Schlacht siehe zuletzt John F. Drinkwater, Alamanni and Rome 213-456. Caracalla to Clovis (Oxford 2007) 237-240.

29 Alexander Demandt, Die westgermanischen Stammesbünde, in: Klio 75 (1993) 387-406.

${ }^{30}$ Gregor von Tours, Historiae II, 9 (ed. Rudolf Buchner, Ausgewählte Quellen zur Deutschen Geschichte des Mittelalters 2-3, Darmstadt ${ }^{8} 2000 /{ }^{9} 2000$ ) 80: De Francorum vero regibus quis fuerit primus, a multis ignoratur. Nam cum multa de eis Sulpici Alexandri narret historia, non tamen regem primum eorum ullatinus nominat, sed duces eos habuisse dicit. Siehe dazu Helmut Reimitz, Die Konkurrenz der Ursprünge in der fränkischen Historiographie, in: Die Suche nach den Ursprüngen. Von der Bedeutung des frühen Mittelalters, ed. Walter Pohl (Forschungen zur Geschichte des Mittelalters 8, Wien 2004) 191-209.

${ }^{31}$ Ian N. Wood, Gregory of Tours and Clovis, in: Revue belge de philologie et d'histoire 63 (1985) 249-272; Goetz, Gens, kings and kingdoms 319-322. 
Reims den Frankenkönig ansippte, ${ }^{32}$ waren wohl nicht zufällig eine königslose Gens. Bei den außerrömischen terwingisch/vesischen Goten herrschten iudices; und die ostgotische Amalergenealogie mussten Cassiodor bzw. Jordanes schon in Theoderichs Großvätergeneration klittern, um eine Herrschaftskontinuität während der Hunnenzeit behaupten zu können. ${ }^{33}$ Bei den Vandalen ebenso wie bei den Langobarden wird das Königtum erst beim Übergang auf Reichsgebiet, 406/407 bzw. ca. 489, deutlich fassbar. ${ }^{34}$ Direkte Verfassungskontinuität zwischen außerrömischem und römischem Königtum lässt sich bei keiner Gens nachweisen. Außerrömische Vorstellungen, über die wir so gut wie gar nichts wissen, mögen bei der Institutionalisierung königlicher Herrschaft über römische Provinzen mitgespielt haben. Doch zeigt das Schicksal der zahlreichen Reichsgründungen auf römischem Boden zur Genüge, dass ,gentile‘ Traditionen in keinem Fall ausreichten, um überregionale Herrschaft aufzurichten und gar zu behaupten. Dazu waren, in unterschiedlichem Maß, römische wie kirchliche Infrastruktur nötig.

Wenig spricht also für die alte Annahme, die frühmittelalterlichen Regna seien einfach eine Schöpfung der eingewanderten Völker, oder, zugespitzter formuliert: das Volk mache den Staat. ${ }^{35}$ Die entgegengesetzte Vorstellung, ethnische Zugehörigkeiten hätten in den Regna überhaupt keine politische Rolle gespielt, wird von Walter Goffart und einigen Schülern mit großem polemischen Aufwand verfochten. ${ }^{36}$ Doch beruht seine Position paradoxerweise auf derselben Vorstellung von ethnischen Identitäten wie die alte Germanenideologie. Er lehnt jede Rolle von Ethnizität in den Regna ab, weil er sie sich nur als Germanentum im herkömmlichen Sinn vorstellen kann. ${ }^{37}$ Das Modell, das hier vorgeschlagen wird, ist ein ganz anderes: Ethnische Identitäten waren ein grundlegendes Element in der politischen Welt der Regna; alle nachrömischen Königreiche (mit der teilweisen Ausnahme Odoakers) hatten einen ethnischen Bezug. Doch beruhte das weniger auf alten Traditionen als auf neuen Möglichkeiten. Dabei mögen vergangene Verhältnisse durchaus eine Rolle gespielt haben; das meiste, was

${ }^{32}$ So berichtet zumindest Gregor von Tours, Historiae II, 31, ed. Buchner 2, 118, der Chlodwig zum „neuen Konstantin“ stilisiert.

${ }^{33}$ Wolfram, Goten 73-83; 250-258. Eine direkte Linie vom ,skythischen` Königtum des Ermanarich zur Vätergeneration Theoderichs ist wegen der vielen Widersprüche in der Genealogie des Jordanes nicht zu belegen; siehe Herwig Wolfram, Die terwingischen Richter und die „älteren“ Balthen, in: ders: Gotische Studien. Volk und Herrschaft im frühen Mittelalter (München 2005) 114-138; ders., Theogonie, Ethnogenese und ein kompromittierter Großvater Theoderichs des Großen, in: Festschrift Helmut Beumann (Sigmaringen 1977) 80-97; sowie Peter J. Heather, The Goths (Oxford/Cambridge, Mass. 1996) 111-116.

${ }^{34}$ Vandalen: Liebeschuetz, Gens into regnum: the Vandals; Guido M. Berndt, Konflikt und Anpassung. Studien zu Migration und Ethnogenese der Vandalen (Husum 2007); anders, mit Verweis auf Spuren eines alten vandalischen Doppelkönigtums: Helmut Castritius, Das vandalische Doppelkönigtum und seine ideell-religiösen Grundlagen, in: Das Reich der Vandalen und seine Vorgeschichte(n), ed. Guido M. Berndt/Roland Steinacher (Forschungen zur Geschichte des Mittelalters 13, Wien 2008) 79-86; Helmut Castritius, Die Vandalen. Etappen einer Spurensuche (Stuttgart 2007). Langobarden: Jarnut, Langobarden; Pohl, Migration und Ethnogenese. Überblick: Wolfram, Das Reich und die Germanen; Pohl, Völkerwanderung.

${ }^{35}$ Walter Schlesinger, Die Grundlegung der deutschen Einheit im frühen Mittelalter, in: ders., Beiträge zur deutschen Verfassungsgeschichte des Mittelalters 2 (Göttingen 1963) 245-285 und 346-348, hier 284: „Das Primäre ist nicht das deutsche Reich, sondern das deutsche Volk“. Dazu Carlrichard Brühl, Deutschland - Frankreich. Die Geburt zweier Völker (Köln/Wien 1990) 710; Walter Pohl, Staat und Herrschaft im Frühmittelalter: Überlegungen zum Forschungsstand, in: Staat im frühen Mittelalter, ed. Stuart Airlie/Helmut Reimitz/Walter Pohl (Forschungen zur Geschichte des Mittelalters 11, Wien 2006) 9-38, hier 11f.; allgemein Goetz, Conclusion.

${ }^{36}$ Siehe zuletzt: Walter Goffart, Barbarian Tides. The Migration Age and the Later Roman Empire (Philadelphia 2006); sowie On Barbarian Identity - Critical Approaches to Ethnogenesis Theory, ed. Andrew Gillett (Turnhout 2002), mit den Einwänden von Walter Pohl, Ethnicity, theory and tradition: a response,in: ebd. 221-240.

${ }^{37}$ Goffart, Barbarian Tides 21, unterstellt den Vertretern der von ihm so genannten ,ethnogenesis theory“, also Wenskus, Wolfram, Geary und dem Autor dieses Artikels, dass sie „German identity“ (also deutsche Identität) aus der Spätantike herleiten wollen: „In its focus on identity and the maintenance of identity and ,ethnic consciousness ‘ by ,kernels of tradition 'over enormous spans of time, ,ethnogenesis theory“ is a subtle device for demonstrating to the Germans of today that they are firmly linked to their ancient ancestors“. Das ist eine völlige Verzerrung meiner Position, siehe etwa Walter Pohl, Der Germanenbegriff vom 3. bis 8. Jahrhundert - Identifikationen und Abgrenzungen, in: Zur Geschichte der Gleichung ,germanisch - deutsch', ed. Heinrich Beck/Dieter Geuenich/Heiko Steuer/Dietrich Hakelberg (RGA Erg. Bd. 34, Berlin/New York 2004) 163-183. Goffart ignoriert völlig, dass die deutsche Sprache anders als die englische ja zwischen Germanen und Deutschen unterscheidet. Dazu, und allgemein zur Debatte um ,Fall Roms‘ oder ,Transformation of the Roman World‘: Walter Pohl, Rome and the barbarians in the fifth century, in: Antiquité Tardive 16 (2008) 93-101. 
wir darüber wissen, verrät aber viel mehr über zeitgenössische Vorstellungen als über authentische Traditionen. Die strukturelle Rolle ethnischer Identitäten im politischen System der Regna entwickelte sich erst mit diesen selbst. Das lässt sich recht gut an der Entwicklung der Königstitel zeigen.

\section{SELBSTAUSSAGEN UND HISTORISCHE AKTEURE}

Sicherlich ist der ethnische Bezug in den Titulaturen und Selbstaussagen der Könige in den Regna nur in einer Minderheit der Fälle bezeugt. ${ }^{38}$ Viele reges bevorzugten wie Theoderich den ,absoluten ' Königstitel ohne ethnischen Bezug. Jordanes berichtet, wie Theoderich nach der Eroberung Italiens die Kleidung seiner Gens ablegte und das Königsgewand als Herrscher über Goten und Römer annahm. ${ }^{39}$ Bei den Franken, wo der absolute Königstitel bereits auf dem Siegelring von Chlodwigs Vater Childerich bezeugt ist, setzte sich die Selbstaussage rex Francorum erst relativ spät durch. ${ }^{40}$ In anderen Regna ist er früher bezeugt, wenn auch teils nur sporadisch. Bei den Westgoten nennt eine Gemme Alarich II. rex Gothorum; in den Variae wird er, da Unterscheidung nötig war, als rex Wisigotharum angesprochen. ${ }^{41}$ Auch Sisebut nennt sich zwischen 616 und 621 in einem Brief an den Langobardenkönig Adaloald rex Wisegotorum; Adaloald wiederum wird korrekt als rex gentis Langobardorum adressiert. ${ }^{42}$ In der Präambel der Lex Burgundionum (zumindest in einigen Handschriften) nennt sich Gundobad vir gloriosissimus Gundobadus rex Burgundionum; die Überarbeitung des burgundischen Gesetzes wird datiert ins zweite Jahr domni nostri gloriosissimi Sigismundi regis, in zwei Extravaganten werden beide rex Burgundionum genannt. Allerdings ist die handschriftliche Überlieferung der Burgundergesetze problematisch. ${ }^{43}$ Bei den Langobardenkönigen lässt sich wahrscheinlich machen, dass sie ihren Titel situativ handhabten. In ihren Leges, die sich vor allem an die Langobarden richteten, nannten sie sich rex gentis Langobardorum, während der Titel in den erhaltenen Königsurkunden, meist für geistliche Empfänger ausgestellt, flavius vir excellentissimus rex oder ähnlich lautet; die älteste etwa an Bobbio: Flavius Agilulf vir excellentissimus rex ... viro venerabili beato Columbano vel sociis eius. ${ }^{44}$ Es blieb also bewusst, dass die gentile Begründung nicht die einzige Legitimierung des Königtums darstellte. In den italischen Königsurkunden war daher paradoxerweise Karl der Große der erste rex Langobardorum. ${ }^{45}$

Drei Beobachtungen lassen sich auf Grund des hier nur exemplarisch skizzierten Befundes machen. Erstens nimmt der Gebrauch des ethnischen Königstitels im Lauf des 5. bis 8. Jahrhunderts eher zu,

${ }^{38}$ Siehe bereits Herwig Wolfram, Intitulatio I. Lateinische Königs- und Fürstentitel bis zum Ende des 8. Jahrhunderts (MIÖG Erg. Bd. 21, Köln/Wien 1967). Freilich hielt Wolfram damals den ,gentilen` Königstitel noch für grundlegend (z. B. Intitulatio 108: „der merowingische Königstitel lautete N. rex Francorum“), während er die absoluten Varianten als ,jüngere Sekundärbildung“ betrachtete (ebd. 55 zum langobardischen Königstitel, der „die ältere Theorie des gentilen Königtums zurückdrängte“). Übersichtliche Zusammenstellung mit teils überzogenen Schlussfolgerungen in der entgegengesetzten Richtung: Andrew Gillett, Was ethnicity politicized in the earliest medieval kingdoms?, in: On Barbarian Identity - Critical Approaches to Ethnogenesis Theory, ed. ders. (Turnhout 2002) 85-122.

39 Jordanes, Getica LVII (ed. Theodor Mommsen, AA 5, 1, Berlin 1882/ND München 1982) 53-138, 134: Suae gentis vestitum reponens, insigne regii amictus, quasi iam Gothorum Romanorumque regnator adsumit. Zum Königtum Theoderichs: Wolfram, Goten 286-289.

${ }^{40}$ Goetz, Gens, kings and kingdoms 323f.; der erste Beleg ist eine kopial überlieferte Urkunde Theudeberts II. von 596.

${ }^{41}$ Cassiodor, Variae III, 1 (ed. Theodor Mommsen, AA 12, Berlin 1898) 78 (falls die Subscriptio authentisch ist); Wolfram, Intitulatio 78.

42 Epistulae Wisigothicae 9 (ed. Wilhelm Gundlach, MGH EE 3, Berlin 1892) 671. In den meisten Epistulae Wisigothicae fehlen leider Adresse und Subscriptio.

${ }^{43}$ Leges Burgundionum, Praef. und Extravagantes XIXf. (ed. Rudolf von Salis, MGH LL nat. Germ. 2, 1, Hannover 1892) 29f. und 118f.; Wolfram, Intitulatio 87; zur Problematik Ian N. Wood, Ethnicity and the ethnogenesis of the Burgundians, in: Typen der Ethnogenese unter besonderer Berücksichtigung der Bayern 1, ed. Herwig Wolfram/Walter Pohl (Wien 1990) 53-69.

44 Codice Diplomatico Longobardo 3, 1 (ed. Carlrichard Brühl, Rom 1973) 6 aus dem Jahr 613; vgl. Walter Pohl, Geschichte und Identität im Langobardenreich, in: Die Langobarden - Herrschaft und Identität, ed. ders./Peter Erhart (Forschungen zur Geschichte des Mittelalters 8, Wien 2005) 555-566.

45 Walter Pohl, Gens ipsa peribit: Kingdom and identity after the end of Lombard rule, in: 774 - ipotesi su una transizione, ed. Stefano Gasparri (Seminari del centro interuniversitario per la storia e l'archeologia dell'alto Medievo 1, Turnhout 2008) 67-78. 
repräsentiert also kaum eine ursprüngliche und erst später durch Akkulturation überformte ,gentile‘ Tradition. Zweitens lässt sich daraus aber keine lineare historische Entwicklung (etwa in Richtung einer zunehmenden Ethnisierung der Regna) ableiten. Eher ging es darum, je nach Situation einen bestimmten Akzent zu setzen oder sich an ein bestimmtes Publikum zu wenden. Für die ersten Jahrhunderte nach dem Fall des weströmischen Reiches lässt sich drittens vermuten, dass Gens und Regnum zwei unterschiedliche soziale Räume bezeichneten. Der König bezog sein Königtum zunächst auf die Gens im engeren Sinn, also diejenigen, die zum Beispiel bei der Promulgation des Edictus Rothari, zur Wahl eines Königs oder zu einem Heerzug zusammenkamen. Das war eine zugleich konkrete und vorgestellte Einheit. Ihr (und nicht einem König oder einer Dynastie) kam wiederum die Herrschaft über das Königreich zu. Doch so unterschiedlich der Gebrauch der ethnischen Legitimation in der Selbstdarstellung der nachrömischen Könige war: Auf römischem Boden entstand eben kein regnum Galliae, Africae oder Britanniae, und auch das regnum Hispaniae und Italiae galt zunächst eher als eines der Goten oder Langobarden. ${ }^{46}$ Die Barbarenherrschaft hat auch nicht, wie öfters in China, zu einem barbarisierten oder partikularen, letztlich aber restaurierten Imperium geführt. ${ }^{47}$

Auch wenn die Spuren der Verwendung ethnischer Selbstbezeichnungen zunächst relativ sporadisch blieben - die Außenwahrnehmung der Regna war von Anfang an von den Gentes geprägt. In der Geschichtsschreibung erfüllte die ethnische Bezeichnung eine offenbar unersetzliche Orientierungsfunktion. Dabei konnten sowohl die römische als auch die biblische Historia als Erzähl- und Deutungsmuster verwendet werden. In flexibler Verbindung mit dem Rex erscheint die Gens als prägender Akteur, der als Kollektiv handlungsfähig ist und das Regnum repräsentiert. Schon Orosius berichtet von der Erhebung des Westgoten Wallia: Successit in regnum ad hoc electus a Gothis. ${ }^{48}$ Langobardi regem sibi statuerunt, heißt es wiederholt bei Paulus Diaconus. ${ }^{49}$ Ähnliches wird von den Franci in den Fredegar-Fortsetzungen und im Liber historiae Francorum erzählt. ${ }^{50}$ Die Fremdwahrnehmung ethnisiert oft und macht so die Geschichte der auswärtigen Beziehungen erzählbar. Die Selbstwahrnehmung differenziert eher und unterstreicht sowohl ein engeres Herkunftsgebiet (Stadt oder Region) als auch breitere, imperiale oder überethnische Herrschaftsansprüche; der ,eigene' Herrscher muss meist nicht eigens bezeichnet werden (auch bei Flavius Josephus ist der König von Juda ,der` basileus). Zunächst bot die lateinische und griechische Historiographie während des Zerfalls des Westreiches Fremdwahrnehmungen; der Aufbau der nachrömischen Regna wurde zeitgenössisch vor allem als Eroberung durch barbarische Gentes beschrieben. Die lateinische Historiographie der Regna verwendete die vertrauten Erzählmuster dann zunehmend zur Selbstdarstellung. Diese Entwicklung lässt sich im Frankenreich von den Chroniken des 5. und frühen 6. Jahrhunderts über Gregor von Tours zu Fredegar verfolgen. ${ }^{51}$ In Spanien greift Isidor von Sevilla die apokalyptische Identifikation der Goten mit Gog und Magog auf und baut sie in ein Lob der Goten ein. ${ }^{52}$ Jordanes, Beda, Paulus Diaconus schreiben die Geschichte der Goten, ,Angeln“ und Langobarden nicht ohne Distanz, aber die ethnische Perspektive ihrer Geschichte ist schon aus der Anlage und zumeist den Titeln ihrer Werke zu erkennen. ${ }^{53}$

${ }^{46}$ Vgl. Hans-Hubert Anton, Antike Großländer, politisch-kirchliche Traditionen und mittelalterliche Reichsbildung, in: Zeitschrift der Savigny-Stiftung für Rechtsgeschichte, kanonistische Abt. 86 (2000) 33-85.

47 Vgl. Rome and China. Comparative Perspectives on Ancient World Empires, ed. Walter Scheidel (Oxford 2009).

48 Orosius, Historia adversus paganos 7, 43, 10.

49 Paulus Diaconus, Historia Langobardorum I, 14 (ed. Ludwig Bethmann/Georg Waitz, MGH SS rerum Langob. et Ital., saec. VI-IX, Hannover 1878) 54: nolentes iam ultra Langobardi esse sub ducibus, regem sibi ad ceterarum instar gentium statuerunt; ebd. III, 16, ed. Bethmann/Waitz 100f.

50 Ian N. Wood, Defining the Franks. Frankish origins in early medieval historiography, in: Concepts of National Identity in the Middle Ages, ed. Simon Forde (Leeds Texts and Monographs NS 14, Leeds 1995) 21-46; Walter Pohl, Zur Bedeutung ethnischer Unterscheidungen in der frühen Karolingerzeit, in: Studien zur Sachsenforschung 12, ed. Hans-Jürgen Hässler (Oldenburg 1999) 193-208.

51 Siehe künftig Helmut Reimitz, Historiographie der Zukunft, sowie ders., The art of truth. Historiography and identity in the Frankish world, in: Texts and Identities in the Early Middle Ages, ed. Richard Corradini/Rob Meens/Christina Pössel/Philipp Shaw (Forschungen zur Geschichte des Mittelalters 12, Wien 2006) 87-104.

52 Isidor von Sevilla, Historia Gothorum (ed. Theodor Mommsen, MGH AA 11, Berlin 1894) 268-295, 268 (De origine Gothorum).

53 Walter Goffart, The Narrators of Barbarian History, A.D. 550-880. Jordanes, Gregory of Tours, Bede and Paul the Deacon (Princeton 1988) sind in diesem Punkt wesentliche Differenzierungen zu verdanken (etwa dass Gregor von Tours 
Retrospektiv können diese Autoren die Entstehung der Regna nun aus der Wanderung von Völkern, als ,Origo gentis‘ erklären. ${ }^{54}$

Die historiographische Erzählung mag, wie meist bei der Beschreibung kollektiven Handelns, vereinfachen und zuspitzen. Andererseits waren die Geschichtsschreiber der Spätantike und des Frühmittelalters durchaus fähig, innerhalb der handelnden Völker ethnische Vielfalt, innere Konflikte und abweichende Handlungsmuster zu erkennen und zu beschreiben. Gens enim aliquos potest habere peregrinos, schreibt Cassiodor und versucht davon die natio abzuheben, die „eines Blutes“ ist, aber auch die patriae gentium, ubi nullus indigena, nullus hospes, nullus peregrinus redderetur exceptus; dabei hatte er wohl das ostgotische Italien seiner Zeit vor Augen. ${ }^{55}$ Die Wahrnehmung der Geschichtsschreiber, dass die Völker politisch agierten, war zwar vereinfacht, aber nicht unangemessen und konnte langfristig wieder das politische Handeln beeinflussen. Kollektiver politischer Akteur im Regnum war zumindest in den zeitgenössischen Vorstellungen die Gens, ebenso wie im Imperium der populus Romanus handelte. Kaum je tritt das Regnum als handelnde Instanz auf, es ist in der Regel Objekt der Herrschaft, territoriale Einheit, gedachte Gemeinschaft oder Inbegriff der königlichen Rechte und bezeichnet den staatliche Rahmen. ${ }^{56}$ Die Gens hingegen ist die Gemeinschaft der politisch Berechtigten, die als Kollektiv ein Herrschaftsrecht, ius, über ein bestimmtes Gebiet erworben hat.

\section{GENS UND HERRSCHAFT}

Isidor von Sevilla berichtet zum Beispiel, Leovigild habe nach seinem Sieg über die Sueben ihr regnum ... in iure gentis suae, nämlich der Westgoten, übertragen.$^{57}$ Dieses ius stellt ein eigenständiges Herrschaftsrecht dar, das in manchen Fällen auch verwehrt werden kann. Laut Paulus Diaconus zogen die zunächst mit den Langobarden nach Italien gekommenen Sachsen wieder ab, da sie noluerunt Langobardorum imperiis subiacere und Alboin ihnen nicht zugestand in proprio iure subsiste$r e .{ }^{58}$ Die rechtsgeschichtliche Forschung hat Letzteres immer auf die Ausübung des eigenen (Volks)Rechtes bezogen und darin den frühesten Beleg für das Prinzip der Personalität des Rechtes gesehen. ${ }^{59}$ Doch Paulus (ebenso wie die Leges Langobardorum) verwendet ius nie in diesem Sinn, sondern als subjektives Herrschafts- oder Besitzrecht. ${ }^{60}$ Das Gegensatzpaar Langobardorum imperia - proprium

keineswegs eine ,Historia Francorum‘ schrieb), doch entfernt er sich zuweilen beträchtlich vom Quellenbefund, um die Rolle der Völker in den jeweiligen Geschichtswerken möglichst zu minimieren.

${ }^{54}$ Herwig Wolfram, Origo gentis; siehe auch, mit etwas anderen Akzenten, Alheydis Plassmann, Origo gentis. Identitätsund Legitimitätsstiftung in früh- und hochmittelalterlichen Herkunftserzählungen (Orbis mediaevalis. Vorstellungswelten des Mittelalters 7, Berlin 2006), die unter diesem Begriff aber eher allgemeine Historiographiegeschichte der Gentes abhandelt; Magali Coumert, Origines des peuples - les récits du haut Moyen Âge occidental, 550-850 (Collection des études augustiniennes 42, Paris 2007). Nebenbei bemerkt, wird in den Origines gentium germanische Herkunft selten hervorgehoben, meist werden - im modernen Sinn - ,germanische` Völker von ,nichtgermanischen` abgeleitet, also aus Troja, aus Skythien oder Mazedonien.

55 Cassiodor, Expositiones in psalmos, ps. 95, 7 (ed. Marcus Adriaen, Magni Aurelii Cassiodori Senatoris Opera II, 2, CC SL 98, Turnhout 1958) 865. Ich danke Herwig Wolfram und Gerda Heydemann für Hinweise zu diesem Punkt.

56 Siehe den Beitrag von Hans-Werner Goetz in diesem Band sowie ders., Regnum. Zu den Definitionen des Staates: Walter Pohl, Staat und Herrschaft im Frühmittelalter: Überlegungen zum Forschungsstand, in: Staat im frühen Mittelalter, ed. Stuart Airlie/Helmut Reimitz/ders. (Forschungen zur Geschichte des Mittelalters 11, Wien 2006) 9-38.

${ }^{57}$ Isidor, Historia Gothorum, ed. Mommsen 287: Leuuigildus ... bellum Suevis intulit regnumque eorum in iure gentis suae mira celeritate transmisit.

58 Paulus Diaconus, Historia Langobardorum III, 6, ed. Bethmann/Waitz 95: Certum est autem hos Saxones ideo ad Italiam cum uxoribus et parvulis advenisse, ut in ea habitare deberent; sed, quantum datur intellegi, noluerunt Langobardorum imperiis subiacere. Sed neque eis a Langobardis permissum est in proprio iure subsistere, ideoque aestimantur ad suam patriam repedasse. Siehe Walter Pohl, Probleme einer Sinngeschichte.

59 So, mit ausführlicher Argumentation gegen meine Position, auf der ich gleichwohl beharren möchte: Gerhard Dilcher, Zur Entstehungs- und Wirkungsgeschichte der mittelalterlichen Rechtskultur, in: Leges - Gentes - Regna. Zur Rolle von germanischen Rechtsgewohnheiten und lateinischer Schrifttradition bei der Ausbildung der frühmittelalterlichen Rechtskultur, ed. Gerhard Dilcher/Eva-Maria Distler (Berlin 2006) 603-638, hier 622-626.

${ }^{60}$ Paulus Diaconus, Historia Langobardorum 1, 12; 1, 25; 4, 34; 4, 37; 5, 34; 6, 28, ed. Bethmann/Waitz 35f.; 62f.; 128; 128-132; 156; 174; sowie Edictus Rothari 319, in: Leges Langobardorum (ed. Friedrich Bluhme, MGH LL 4, Hannover 1868) 3-90, 73f. und Liutprand 18, 57, und 70, in: ebd. 96-182, 115; 130; 135f.; und eine Reihe von Belegstellen im Co- 
ius macht deutlich, worum es ging. Die gens Langobardorum hatte das Herrschaftsrecht über Italien erworben und wollte keiner anderen Gens einen Anteil daran überlassen. Aus der Sicht der Origo gentis Langobardorum wurde Alboin im Jahr 569 als Langobardenkönig mit der Besetzung von Mailand zugleich zum dominus Italiae. ${ }^{61}$ Ähnlich formuliert der Prolog der Capitularien des Arichis von Benevent 866, Gott habe einst Italiae regnum genti nostrae Langobardorum unterworfen; später kam das Volk der Franken (hier Gallorum gens genannt), das 774 primatum et capud regni illius invasit, also die Ansprüche der gens Langobardorum an sich riss. Regnum und Gens sind hier nicht identisch, werden aber zugleich der fränkischen Herrschaft unterstellt: regnum Italiae gentemque Langobardorum suo imperio subdidit. ${ }^{62}$ Damit ist, aus der Sicht des Paulus Diaconus, die gens Langobardorum (als herrschaftsberechtigter Verband) untergegangen, obwohl ihre Mitglieder weiterleben, ja in ihrem Namen weiter Herrschaft ausgeübt wird, allerdings von fränkischen Königen. Adelchis hatte, nach dem Zeugnis seines Prologs, weiterhin den Prinzipat von Benevent inne, ducatum ipsius reliquiarum gentis.

In ähnlichem Sinn, wenn auch allegorisch stellt Isidor in der Einleitung zu seiner Historia an den Schluss seines Lobs der Spania die Herrschaftsübernahme durch die Goten als zunächst etwas gewaltsame Liebesgeschichte dar: Zuerst habe Rom als caput gentium die Spania begehrt und siegreich zur Ehe gezwungen, dann aber habe nach vielen Siegen die gens Gothorum sie geraubt und geliebt: denuo tamen Gothorum florentissima gens post multiplices in orbe victorias certatim rapuit et amavit. ${ }^{63}$ Es folgt ganz sinngemäß der Abschnitt De origine Gothorum mit der Ableitung der Gens von Gog und Magog sowie den Skythen. Vom caput gentium war die Herrschaft, ebenso kollektiv, auf die würdigste der Gentes übergegangen. Es ist interessant, dass Rom hier nicht selbst als Gens gesehen wird, sondern als ,Haupt‘ der Gentes, von denen die erfolgreichste die Spania schließlich dem Imperium entreißen kann.

Semantisch ist die Gens als politischer Akteur oft fast austauschbar mit dem König, der als ihr Repräsentant handelt. Sein Bezug zur Gens ist aber komplizierter. Genau genommen ist ein Titel wie rex Francorum mehrdeutig. Er kann die Herkunft bezeichnen, zum Beispiel bei den reges Alamannorum bei Ammianus Marcellinus, die nicht Könige über die Alemannen sind, sondern eher alemannische Könige. Er benennt die Herrschaft über die Gens, aber auch die Herrschaft im Namen der Gens über ein Regnum, das nicht nur sie umfasst. Wenn Beda über den anglischen König Penda berichtet, er habe seinen Sohn als König regno gentis illius vorangestellt, so lässt sich das wie viele ähnliche Formulierungen doppelt auffassen: Das Regnum gehörte den Angeln, und es herrschte über die Angeln. ${ }^{64}$

Das Regnum (das Königreich) hatte meist einen wesentlich weiteren Umfang als die Gens, der dieses Regnum zukam. Ein König konnte auch über mehrere Gentes herrschen wie Odoaker. ${ }^{65}$ In der Regel, wie bei Langobarden und Franken, wurden diese Gentes bald als Bestandteile der herrschenden Gens angesehen. ${ }^{66}$ Alternative ,barbarische' Identitäten (etwa der Alanen im Vandalenreich, der Rugier im Ostgotenreich oder der Burgunder und Sachsen im fränkischen Gallien) wurden zwar nicht ausgelöscht, aber zurückgedrängt. Insgesamt stellten die Barbaren in ihren Reichen jeweils eine kleine Minderheit dar. Längerfristig musste das zu tiefgreifenden Identitätsverschiebungen führen. Dabei wurden zwei ethnische Prozesse wirksam: Erstens stabilisierten der politische Erfolg und die dadurch errungenen Privilegien die Gens im engeren Sinn, nämlich den herrschenden Verband der Krieger, der

dice diplomatico Longobardo (ed. Luigi Schiaparelli/Carlrichard Brühl/Theo Kölzer/Herbert Zielinski, Fonti per la Storia d’Italia 62-66, 5 Bde., Roma 1929-2002).

61 Origo gentis Langobardorum 5 (ed. Ludwig Bethmann/Georg Waitz, MGH SS rerum Langob. et Ital., saec. VI-IX, Hannover 1878) 1-6, hier 4.

62 Capitula domni Adelchis (ed. Friedrich Bluhme, MGH LL 4, Hannover 1868) 210-212, hier 210. Pohl, Gens ipsa peribit.

63 Isidor von Sevilla, De laude Spaniae (ed. Theodor Mommsen, MGH AA 11, Berlin 1894) 267.

${ }^{64}$ Beda Venerabilis, Historia ecclesiastica gentis Anglorum 3, 21 (ed. John E. King, Loeb Classical Library, CambridgeMass./London 1979) 430: Peada praelatus est a padre regno gentis illius. Eindeutiger ist in einem ähnlichen Fall Jordanes, Getica LVII, ed. Mommsen 132; Theoderich wird von Thiudimir erhoben: Theoderico vero gentis suae regem audiens ordinato imperator Zeno grate suscepit.

65 Paulus Diaconus, Historia Langobardorum 1, 19, ed. Bethmann/Waitz 57: Odoacar gentibus quae eius dicioni parebant, id est Turcilingis et Herolis Rugorumque parte, quos iam dudum possidebat, necnon etiam Italiae populis, venit in Rugiland.

${ }^{66}$ Paulus Diaconus, Historia Langobardorum 1, 20, ed. Bethmann/Waitz 59: Langobardi ditiores effecti, aucto de diversis gentibus, quas superaverant. 
übrigen freien Mitglieder und ihrer Familien. Das zeigt sich deutlich am raschen Zerfall derjenigen Gentes, denen eine Reichsgründung auf römischem Boden nicht gelang oder deren Regnum unterging. Paulus Diaconus setzt nicht nur im Fall der Langobarden selbst, sondern auch bei den Erulern und Gepiden den Verlust des Königtums mit dem weitgehenden Verlust ethnischer Identität gleich. ${ }^{67}$ Die Könige der Völkerwanderungszeit benötigten bedeutende Mittel, um ihre Herrschaft aufrechtzuerhalten. Angriffskriege und Plünderungszüge, römische Jahrgelder und Tribute barbarischer Bauern boten (außer im Sonderfall der Steppenreiche) keine zureichende Grundlage für dauerhafte großräumige Herrschaft. Seit im 4./5. Jahrhundert Barbaren in führenden Positionen an den Reichtümern der römischen Welt partizipieren konnten, stiegen die Ansprüche der Krieger auch an der Peripherie des Imperiums. Das führte vor allem an der mittleren Donau zu ausweglosen Konfliktlagen, in denen die Reiche der Sueben, Sarmaten, Rugier, Eruler und schließlich Gepiden untergingen. ${ }^{68}$

Erst die Ansiedlung auf Reichsboden machte eine stabile Versorgung der Barbarenkrieger möglich und damit zugleich eine dauerhafte Mitgliedschaft bei der herrschenden Gens attraktiv. Letztlich ging es den neuen militärischen Eliten barbarischer Herkunft um den Besitz von Land, das weiterhin von abhängigen Produzenten bewirtschaftet wurde. ${ }^{69}$ Die privilegierte Stellung der herrschenden Gens musste zugleich zur einer gewissen Abschließung nach außen führen. Dieses Privileg nennt Cassiodor libertas Gothorum, die gotische Freiheit. ${ }^{70}$ An der Unterscheidbarkeit der herrschenden Gens wurde oft gerade dann festgehalten, wenn die Grenzen zu verschwimmen drohten. Nirgends wurde zum Beispiel die Besonderheit der Langobarden, der gens Bardorum, in Inschriften, Gedichten und Chroniken so betont wie im Süditalien des 9. und 10. Jahrhunderts, wo sich die langobardische Führungsschicht kaum mehr von ihrer romanisch geprägten Umwelt unterschied. ${ }^{71}$

Der zweite ethnische Prozess wirkte längerfristig und öffnete die Gens für die ansäßige Bevölkerung. Sozialer Aufstieg, die Orientierung an lokalen Führungsgruppen oder generationenlange Zugehörigkeit zu einem Herrschaftsverband konnten zur schrittweisen Übernahme der dominierenden ethnischen Identität führen. Über diesen Prozess wissen wir kaum etwas, da er in unseren Quellen noch viel weniger wahrgenommen wurde als die Aufnahme von Barbarengruppen anderer Herkunft. Wir können ihn aber aus dem Ergebnis erschließen, nämlich einer westfränkisch-französischen ebenso wie einer lombardischen Mehrheitsbevölkerung, die den Namen der herrschenden Gens und die Sprache der Bevölkerungsmehrheit übernommen hatte. Beide Prozesse, Distinktion und Integration, waren aber eng verflochten. Auch Römer konnten in die militärische Führungsschicht aufsteigen, Franken oder Langobarden der Unterschicht angehören. Wie identitätswirksam ethnische Zugehörigkeiten in den frühmittelalterlichen Regna jeweils waren, konnte auch sehr unterschiedlich sein.

Jan Assmann hat zu Recht zwischen ethnischen Grundstrukturen, nämlich den lokalen und regionalen Gemeinschaften (wie es auch die germanischen Gentes der frühen Kaiserzeit waren), und den

${ }^{67}$ Paulus Diaconus, Historia Langobardorum 1, 20, ed. Bethmann/Waitz 59; ebd. 1, 27, ed. Bethmann/Waitz 69f.; ebd. 5, 6, ed. Bethmann/Waitz 146f.

${ }^{68}$ Walter Pohl, Die Gepiden und die Gentes an der mittleren Donau nach dem Zerfall des Attilareiches, in: Die Völker an der mittleren und unteren Donau im 5. und 6. Jahrhundert, ed. Herwig Wolfram/Falko Daim (Denkschriften der Österreichischen Akademie der Wissenschaften 145, Wien 1980) 240-305.

69 Siehe Anerkennung und Integration. Zu den wirtschaftlichen Grundlagen der Völkerwanderungszeit, 400-600, ed. Herwig Wolfram/Andreas Schwarcz (Denkschriften der Österreichischen Akademie der Wissenschaften, Phil.-Hist. Kl. 193, Wien 1988); in manchen Fällen wurden barbarische Soldaten wohl anfangs auch mit Steueranteilen versorgt, wie das Walter Goffart, Barbarians and Romans, A.D. 418-584. The Techniques of Accommodation (Princeton 1980), vorgeschlagen hat (mit Ergänzungen in ders., Barbarian Tides 119-186). Siehe dazu aber auch die Diskussion in Kingdoms of the Empire. The Integration of Barbarians in Late Antiquity, ed. Walter Pohl (The Transformation of the Roman World 1, Leiden/New York/Köln 1997). Chris Wickham, Framing the Early Middle Ages. Europe and the Mediterranean, 400-800 (Oxford 2005), sieht im Wandel von der Finanzierung der Armee aus dem Steuersystem zu ihrer Erhaltung aus eigenem Landbesitz den entscheidenden Übergang vom antiken zum mittelalterlichen Staat, dessen Kontrolle über die bewaffnete Macht dadurch schwächer wurde.

${ }^{70}$ Cassiodor, Variae V, 30 (ed. Theodor Mommsen, MGH AA 13, Berlin 1898) 160; Wolfram, Goten 301; ders., Suche nach den Ursprüngen 235.

${ }^{71}$ Walter Pohl, Werkstätte der Erinnerung. Montecassino und die langobardische Vergangenheit (MIÖG Erg. Bd. 39, Wien 2001). 
„Steigerungsformen“ überregionaler Herschaft und Ethnizität unterschieden. ${ }^{72}$ In den frühmittelalterlichen Regna waren beide Formen von Ethnizität allerdings verflochten. Franken, Goten oder Langobarden geboten über Gebiete im Ausmaß moderner europäischer Großstaaten. Ihr Zusammenhalt verdankte sich allerings zumindest teilweise den Mechanismen einer face-to-face-group. Regelmäßige Kriegszüge und Zusammentreffen bei Hof halfen dabei, persönliche Bekanntschaften und Freundschaftsnetzwerke aufzubauen und aufrechtzuerhalten, ohne die eine Integration der Reiche des Frühmittelalters nicht möglich gewesen wäre. ${ }^{73}$ Die Vorstellung von der Gens setzte ein gewisses Ausmaß an tatsächlicher Gemeinschaftserfahrung voraus, genauso wie die gemeinsame Messfeier den populus Christianus vorstellbar machte. Man sollte daraus aber nicht schließen, dass diese Netzwerke und das aus regelmäßigem persönlichen Kontakt entstehende Gemeinschaftsgefühl an der Stelle des Staates die großräumige Integration leisteten. Denn es waren ja die Zwecke und Mittel des Staates, die all diese Leute, teils über große Entfernungen hinweg, zusammenbrachten. Die Aufrechterhaltung des staatlichen Rahmens über alle inneren Konflikte hinweg war nicht selbstverständlich, wie die Beispiele Süditaliens im 9. und Frankreichs im 10./11. Jahrhundert zeigen. Das regnum Francorum erforderte eine ,Steigerungsform' der Ethnizität, und bediente sich zugleich des Potentials ethnischer Grundstrukturen, die in den Chroniken der gens Francorum im engeren Sinn entsprechen.

Diejenigen, die im Namen der Gens handeln, werden dabei terminologisch nicht von der gesamten Gens geschieden. Das lässt sich besonders gut an den Continuationes Fredegars und dem Liber historiae Francorum im 8. Jahrhundert beobachten. Omnes Franci beschließen bespielsweise, sicut mos Francorum est, 754 in Berny-Rivière den Zug gegen Aistulf. ${ }^{74}$ Auf Grund eines consilium mit seinen proceres zieht Pippin nun cum ... reliquas nationes, qui in suo regno commorabantur, et Francorum agmina gegen die Langobarden. Nach der Niederlage wendet sich Aistulf mit der Bitte um Frieden an die obtimates Francorum, was ihm dann per iudicio Francorum zu Teil wird, und so weiter. ${ }^{75}$ Der Begriff Franci konnte in unterschiedlichen Zusammenhängen die proceres und maiores natu, den jeweiligen exercitus oder alle freien Franken bedeuten oder durch die Entscheidung des Königs repräsentiert werden. ${ }^{76}$ Diese begriffliche Ambivalenz entstand aber nicht unbedingt aus Beliebigkeit, sondern aus dem situativen Gebrauch. So wurde gestufte und flexible politische Partizipation möglich. Die Franci wurden als konkrete, bis zu einem gewissen Grad untereinander persönlich bekannte Führungsgruppe und im Prinzip als Abstammungsgemeinschaft vorgestellt; ihr Umfang war je nach Situation ganz unterschiedlich. Gerade deshalb setzte politisches Handeln im Frankenreich letztlich ein abstraktes Verständnis von Gens voraus, da es ja ständige pragmatische Entscheidungen über die jeweilige Bezugsgruppe erforderte. ${ }^{77}$ Unterschiedliche Akteure - König, Hof, Mächtige und Amtsträger, Heer, christlicher Populus - handelten im Horizont von Regnum und Gens, was die Kontingenz ihres Handelns einschränkte. Das setzte ein zumindest implizites Wissen über Handlungsräume, Spielregeln und das Zusammenspiel der Akteure voraus, das in Konflikten immer wieder präzisiert und verdeutlicht wurde. Entscheidend am Frankenbegriff des 8. Jahrhunderts war die politische Handlungsfähigkeit auf der Ebene des Regnum (oder der Regna).

Ein ähnliches Spannungsverhältnis zwischen konkreter Verkörperung und abstraktem Verständnis von Gens und Regnum findet sich auch im Westgotenreich. Nach den Konfiskationen der Besitzungen

72 Jan Assmann, Das kulturelle Gedächtnis: Schrift, Erneuerung und politische Identität in frühen Hochkulturen (München 1992) 144-160; Walter Pohl, Identität und Widerspruch. Gedanken zu einer Sinngeschichte des Frühmittelalters, in: Die Suche nach den Ursprüngen. Von der Bedeutung des frühen Mittelalters, ed. Walter Pohl (Forschungen zur Geschichte des Mittelalters 8, Wien 2004) 23-36.

${ }^{73}$ Siehe Gerd Althoff, Verwandte, Freunde und Getreue. Zum politischen Stellenwert der Gruppenbindungen im frühen Mittelalter (Darmstadt 1990).

74 Continuationes Fredegarii 37-38 (ed. Bruno Krusch, MGH SS rer. Merov. 2, Hannover 1888) 168-193, hier $183-185$. Siehe auch Goetz, Gens, kings and kingdoms, bes. 334-338.

75 Continuationes Fredegarii 38, ed. Krusch 185.

${ }^{76}$ Eine solche „Verallgemeinerung von Sinnorientierungen“ erlaubte es, im Luhmannschen Sinn, in ganz verschiedenen Situationen ähnliche Konsequenzen zu ziehen: Niklas Luhmann, Macht (Stuttgart ${ }^{3} 2003$ ) 31.

77 Auch Johannes Fried, Gens und Regnum. Wahrnehmungs- und Deutungskategorien politischen Wandels im früheren Mittelalter. Bemerkungen zur doppelten Theoriebindung des Historikers, Sozialer Wandel im Mittelalter. Wahrnehmungsformen, Erklärungsmuster, Regelungsmechanismen, ed. Jürgen Miethke/Klaus Schreiner (Sigmaringen 1994) 73104, geht davon aus, dass Gens im Frankenreich einen Begriff mit relativ hohem Abstraktionsniveau darstellte. 
konkurrierender Adelsgruppen durch Chindaswinth wurde Ende 653 auf dem 8. Konzil von Toledo geklagt, dass cuncta totius gentis membra vacuata languescerent, während nur der Bauch des Princeps gefüllt sei. ${ }^{78}$ Die von der Verfolgung betroffenen führenden Familien sind also die ,gesamte Gens'. Das ist aber derselbe Zusammenhang, in dem der kategorische Satz fällt: regem iura faciunt, non persona, die Herrschaftsrechte, nicht die Person machen den König, eine Vorstellung, die dem ,dunklen` Frühmittelalter keineswegs fremd ist. ${ }^{79}$

Die ethnische Benennung eines Herrschaftraumes hatte also nichts mit tatsächlicher Einheitlichkeit der Bevölkerung zu tun. Sie formulierte den Anspruch der Gens auf die Herrschaft über ein Territorium, eine Patria oder Provincia. Sekundär konnte der Herrschaftstitel dann auch auf ein ethnisch benanntes Territorium (Francia, Anglia, Hungaria) bezogen werden. Die herrschende Gens war bis zu einem gewissen Grad offen, definierte sich aber weiterhin aus gemeinsamer Herkunft und Geschichte. Das Regnum wurde daher zum Katalysator ethnischer Prozesse. Letztlich konnten so die Franken zu einem romanischen Volk werden, die Bulgaren zu einem slawischen. Der wesentliche Unterschied gegenüber den außerrömischen ist bei den nachrömischen Regna die relativ stabile überregionale Ausdehnung der Herrschaft. Im kaiserzeitlichen Barbaricum war regionale Königsherrschaft dauerhafter als überregionale (wie bei Ariovist, Marbod, Arminius, Ermanarich oder Attila). Bei den nachrömischen Regna war das umgekehrt; Rugier, Burgunder, Thüringer, Alemannen, spanische Sueben, die angelsächsischen Regionalreiche sind untergegangen oder in größeren Einheiten aufgehoben worden, nur die größten Reiche konnten sich behaupten. Das Regnum schuf die Voraussetzung dafür, dass eine Gens sich in der politischen und ethnischen Landschaft der Zeit behaupten und entwickeln konnte.

Die Wahrnehmung der Zeitgenossen von ethnischen und politischen Prozessen war sicherlich unvollständig. Doch stand ihnen mit der lateinischen Staatssprache ein differenziertes Instrument zur Verfügung, das staatliches Handeln beschrieb und über ein vielfältiges Vokabular verfügte. ,Gens‘ fügt sich in ein komplexes frühmittelalterliches Begriffsfeld politischer Integration ein. Regnum, Gens, Populus, Patria, Ecclesia und Res publica beschrieben Aspekte der begrifflichen wie institutionellen Ordnung frühmittelalterlicher Großverbände. Die lateinische Begriffssprache der Zeit war den politischen Verhältnissen nicht äußerlich, sondern stattete sie erst mit Sinn aus. Macht setzt ja ständige (wenn auch nicht notwendigerweise verbale) Kommunikation voraus. ${ }^{80}$ Dabei mögen Rituale, Verwandtschaftsbeziehungen, Tauschverhältnisse, Festkultur, Performanz und eine Anwesenheitsgesellschaft von Kriegern eine wichtige Rolle gespielt haben. Doch genügte das kaum für die Stabilisierung weiträumiger Königreiche auf römischem Boden. Immerhin erlaubte die politische Kultur der Zeit tatsächlich die bleibende Integration von großen Gebieten, deren Zugehörigkeit zum jeweiligen Regnum nur in Ausnahmsfällen in Frage stand. Der politische Diskurs der Zeit muss dem Kommunikationszusammenhang also einigermaßen angemessen gewesen sein. Die römische rhetorischpolitische Tradition wurde dabei ergänzt von christlichem Gemeinschaftsbewusstsein. ${ }^{81}$

\section{CHRISTLICHE LEGITIMATION VON REGNUM UND GENS}

Das Christentum spielte bei der Entwicklung der ethnischen ,Staaten` des Frühmittelalters eine entscheidende Rolle. Stabile großräumige Regna konnten nur auf christlicher Grundlage entstehen. ${ }^{82}$ Institutionell bedeutete das eine Zusammenarbeit von Königen und Bischöfen, militärischen und kirchlichen Eliten. Das Verhältnis von Remigius von Reims zu Chlodwig oder von Avitus von Vienne

\footnotetext{
${ }^{78}$ Concilium Toletanum VIII, Decretum iudicii universalis editum in nomine principis (ed. José Vives, Concilios visigóticos e hispano-romanos, Barcelona 1963) 455.

${ }^{79}$ Concilium Toletanum VIII, ed. Vives 452.

${ }^{80}$ Siehe Luhmann, Macht.

${ }^{81}$ Die Rezeption biblischer Modelle in Exegese und Predigt, politischer Liturgie und Historiographie bildet ein zentrales Thema des Wiener Wittgenstein-Projektes „Ethnische Identitäten im frühmittelalterlichen Europa“. Siehe dazu auch künftig die geplante Dissertation von Gerda Heydemann, Exegese von Identität und Differenz: Religiöse und ethnische Identitäten in frühmittelalterlichen Kommentaren zum Alten Testament.

${ }^{82}$ Pohl, Ethnische Wende. Eine Ausnahme bildeten die Steppenvölker, die aber letztlich entweder christianisiert wurden (Bulgaren, Ungarn) oder verschwanden (Hunnen, Awaren).
} 
zu den Burgunderkönigen kann als Beispiel dienen. ${ }^{83}$ Dabei war die Autorität der Bischöfe der Macht der Könige nicht immer unterlegen; Avitus brachte König Sigismund nach einer Phase enger Kooperation wegen seiner hohen moralischen Anforderungen stark unter Druck. Doch in der Regel stützten kirchliche Autoritäten in Lehre, Predigt und Gebet, bei der Legitimation von Herrschaft und Kriegen die einzelnen Königreiche, auch wo es gegen christliche Gegner ging. Die Laudes des Herrschers sollten für den Schutz des Himmels über den Herrscher und seine Familie sorgen ${ }^{84}$ Eine immer weiter ausgefeilte Liturgie des Krieges wurde zum unverzichtbaren Bestandteil der psychologischen Kriegführung; auch der Triumph wurde christianisiert. ${ }^{85}$ In der Karolingerzeit häuften sich die Versuche, alle Mitglieder der gens Francorum und alle Bewohner des Königreiches zum Gebet für das Heer und damit zum spirituellen Mitkämpfen gegen die Feinde zu veranlassen. ${ }^{86}$ Die kontrovers diskutierte Lehre von der militia Christi und vom ,gerechten Krieg' bot einen christlichen Rahmen für die Kampfeslust der militärischen Eliten der Regna. ${ }^{87}$ Oft wird die ,Gentilisierung ‘ einer an sich universalen Religion für eine solche Legitimierung der Kämpfe unter christlichen Völkern verantwortlich gemacht. ${ }^{88}$ Doch bot schon das Alte Testament eindrucksvolle Vorbilder für den Kampf der Völker und ihre heilsgeschichtliche Interpretation.

Nicht nur die Regna, auch die Gentes waren christlich legitimiert. Die Bibel stellte ein differenziertes (wenn auch keineswegs widerspruchsfreies) Modell für das Verständnis einer Welt von Gentes zur Verfügung. ${ }^{89}$ Im Alten Testament fand sich sowohl ein faszinierendes Vorbild für die Selbstidentifikation eines Volkes im Bund mit Gott als auch für das ständige Drama der Auseinandersetzungen mit anderen Völkern, deren Angriffe oft als göttliche Strafe oder Prüfung gedeutet werden konnten. Die vielfältigen Sinnangebote des Alten Testamentes für ethnische Szenarien wurden im Mittelalter häufig rezipiert, sowohl in der Selbstwahrnehmung (etwa die Franken als das Neue Israel) als auch zur Deutung feindlicher Angriffe. ${ }^{90}$ Der Bund Gottes mit der gens Israel bedeutete für die spätantike und frühmittelalterliche Exegese eine ständige Herausforderung. Oft wurden die Christen insgesamt als das

${ }^{83}$ Siehe den Beitrag von Ian N. Wood, in diesem Band; Avitus of Vienne - Letters and Selected Prose (übers. Danuta Shanzer/ders., Liverpool 2002) bes. 13-23; Wood, Kingdom of the Gibichungs; sowie die Beiträge von Mayke de Jong und Steffen Patzold, in diesem Band.

${ }^{84}$ Grundlegend: Ernst H. Kantorowicz, Laudes Regiae: A Study in Liturgical Acclamations and Medieval Ruler Worship (Berkeley 1946).

${ }^{85}$ Michael McCormick, Eternal Victory. Triumphal Rulership in Late Antiquity, Byzantium and the Early Medieval West (Cambridge 1986); Walter Pohl, Liturgie di guerra nei regni altomedievali, in: Rivista di Storia del Cristianesimo 5/1 (2008) $29-44$.

${ }^{86}$ Pohl, Liturgie di guerra 39f.

87 Zum westgotischen Bereich: Alexander Bronisch, Reconquista und Heiliger Krieg. Die Deutung des Krieges im christlichen Spanien von den Westgoten bis ins frühe 12. Jahrhundert (Spanische Forschungen der Görresgesellschaft 2/35, Münster 1998); ders., Die westgotische Reichsideologie und ihre Weiterentwicklung im Reich von Asturien, in: Das frühmittelalterliche Königtum. Ideelle und religiöse Grundlagen, ed. Franz-Reiner Erkens (RGA Erg. Bd. 49, Berlin/New York 2005) 161-189; ders., Die Judengesetzgebung im katholischen Westgotenreich von Toledo (Hannover 2005). Ich danke Gerd Kampers, Bonn, für die Hinweise; allgemein: Militia Christi e Crociata nei secoli XI-XIII, Atti della undicesima Settimana internazionale di studio, Mendola 1989 (Milano 1992), vor allem mit den Beiträgen von Jean Leclercq, ,Militare Deo‘ dans la tradition patristique, in: ebd. 3-20; Réginald Grégoire, Esegesi biblica e ,militia Christi`, in: ebd. 21-48; und Friedrich Prinz, Primi stadi della ,militia Christi` altomedievale nella tarda antichità e nel sistema ecclesiastico imperiale del periodo carolingio e degli Ottoni, in: ebd. 49-63.

88 So etwa Arnold Angenendt, Der eine Adam und die vielen Stammväter. Idee und Wirklichkeit der Origo gentis im Mittelalter, in: Herkunft und Ursprung. Historische und mythische Formen der Legitimation. Akten des Gerda Henkel Kolloquiums 13.-15. Oktober 1991, ed. Peter Wunderli (Sigmaringen 1994) 27-52; Lutz von Padberg, Unus populus ex diversis gentibus. Gentilismus und Einheit im früheren Mittelalter, in: Der Umgang mit dem Fremden in der Vormoderne, ed. Christoph Lüth/Rudolf W. Keck/Erhard Wiersing (Beiträge zur historischen Bildungsforschung 17, Köln/Weimar/Wien 1997) 155-193.

${ }^{89}$ Walter Pohl, Die ,ethnische Wende‘ des Frühmittelalters und ihre Folgen, gehalten am 19. Mai 2006 (Antrittsvorlesungen Gastbeitrag von Walter Pohl, Universität Wien). Immer noch wertvoll ist die breite Materialsammlung bei Arno Borst, Der Turmbau von Babel. Geschichte der Meinungen über Ursprung und Vielfalt der Sprachen und Völker, 4 Bde. (Stuttgart 1957-1963).

90 Siehe Mary Garrison, The Franks as the New Israel? Education for an identity from Pippin to Charlemagne, in: The Uses of the Past in the Early Middle Ages, ed. Yitzhak Hen/Matthew Innes (Cambridge 2000) 114-161, mit eher vorsichtiger Interpretation. 
Neue Israel verstanden. Im Frühchristentum war dementsprechend die Vorstellung von den Christen als eigener Gens verbreitet. ${ }^{91}$ Spätere exegetische Autoren haben diese Ansicht eher zurückgewiesen und eine bloß allegorische Identifikation zwischen Israel und dem populus Christianus vorgezogen. ${ }^{92}$

Das Neue Testament ist in diesem Punkt ambivalent. Paulus betonte die Einheit der Völker im Volk Gottes: Wo der Mensch nach dem Bildnis des Schöpfers erneuert wird, so heißt es im Kolosserbrief (Kol 3,11), dort „gibt es nicht mehr Griechen oder Juden, Beschnittene oder Unbeschnittene, Fremde, Skythen, Sklaven oder Freie, sondern Christus ist alles und in allen." ${ }^{933}$ Doch hieß es am Ende des Matthäusevangeliums, „gehet zu allen Völkern, und macht alle Menschen zu meinen Jüngern“ (Mt 28, 19), und bei Markus (Mk 13, 10) „Vor dem Ende aber muss allen Völkern das Evangelium verkündet werden“. Eine Welt der Völker entsprach nach der Bibel durchaus dem göttlichen Heilsplan. In der Polemik des 5. Jahrhunderts um die Prädestination entwickelte Prosper in seinem Traktat De vocatione omnium gentium die heilsgeschichtliche Rolle der Völker: Denn es war klar, dass nicht allen Individuen gleichermaßen der göttlichen Gnade teilhaftig geworden waren; doch würden bis zum Ende der Zeiten alle Völker zum Heil berufen werden, wodurch sich die göttliche Gerechtigkeit äußerte. ${ }^{94}$ Das Christentum machte in diesem Sinn die Gentes - im doppelten Sinn von ,Völkern` und ,Heiden ‘ - zu seinem Horizont, den es erst im Lauf der Jahrhunderte auszufüllen vermochte. Die christlichen Missionsbemühungen konnten durchaus das Zugehörigkeitsbewusstsein zur Gens verstärken. Dass etwa England noch heute so heißt, lag wohl an Bedas Stilisierung der Historia ecclesiastica gentis Anglorum. ${ }^{95}$

Die Diskussionen um die Rolle der Gentes in der Heilsgeschichte trugen jedenfalls dazu bei, den Begriff providentiell aufzuladen. Einerseits war er seit der Spätantike mit ,Heiden` und damit negativ konnotiert. Andererseits behielt er seine positive Identifikationsfunktion. Es ist bemerkenswert, dass im Frühmittelalter ausgerechnet jener Begriff ethnische Identität beschreibt, der zugleich die Alterität der Heiden und Barbaren bezeichnet. Das Christentum bewirkte also bis zu einem gewissen Grad eine Transformation der ethnischen Begrifflichkeit. Zum Unterschied von den Theogonien oder den Vorstellungen von Auserwähltheit vieler nichtchristlicher Völker entsprach aus christlicher Sicht auch die Vielheit der Völker dem göttlichen Heilsplan, solange sie letztlich in Christus aufgehoben werden konnte. Diese Dynamik war es wohl, die den Erfolg der ethnisch begründeten Königreiche erklärt und sich bis zur modernen Nation als Gegenstand einer Ersatzreligion steigern ließ.

Die frühmittelalterlichen Regna hatten also einen zweifachen Bezug zum ,Volk`, und zwar den populus Christianus und die Gens. Meist umfasste eine Gens mehrere populi, die als konkrete Kirchengemeinden vorgestellt werden konnten; seltener wurde die Gens ausdrücklich als Teil eines umfassenderen christlichen Populus hervorgehoben. Im karolingischen Frankenreich wurde versucht, Gens, Populus und Ecclesia möglichst in Einklang zu bringen. ${ }^{96}$ Diese doppelte Legitimierung drückt sich in Titeln aus, die das Königtum sowohl von Gott als auch von der Gens ableiten (z.B. Gratia Dei N. rex Francorum). Das Verständnis der herrschenden Ordnung als Glaubensgemeinschaft ist dem spätrömischen Reich und seinen Nachfolgekulturen, auch Byzanz und der islamischen Welt, gemeinsam. Was den lateinischen Westen unterscheidet, ist die zusätzliche Ableitung überregionaler Herrschaft von der Gens. Dabei verschränkten sich die Vorstellungen vom durch politische Mitwirkung und als christli-

${ }^{91}$ Denise Buell, ,Why this New Race‘: Ethnic Reasoning in Early Christianity (New York 2005); vgl. dies., Race and universalism in early Christianity, in: Journal of Early Christian Studies 10/4 (2002) 429-468. Dieser Abschnitt verdankt wesentliche Anregungen den Arbeiten von Gerda Heydemann, Wien.

92 Siehe etwa Prosper, In Psalmos, Ps. 104, PL 51, 326b: Populus Christianus verus est Israel. Der Exodus Israels aus Ägypten wird verglichen mit der Bekehrung, die als Auszug aus dem barbarische Volk verstanden wird: exisse de populo barbaro.

${ }^{93}$ In diesem Sinn auch Joseph Ratzinger, Die Einheit der Nationen - Eine Vision der Kirchenväter (Salzburg ${ }^{22005}$ $\left.\left[{ }^{1} 1971\right]\right)$.

94 Prosper, De vocatione omnium gentium, transl. Prudentius de Letter (= Ancient Christian Writers 14, London 1952).

95 Patrick Wormald, Bede, the Bretwaldas and the origins of the gens Anglorum, in: Ideal and Reality in Frankish and Anglo-Saxon Society, ed. Patrick Wormald/Donald Bullough (Oxford 1983) 99-129; ders., Engla Lond: the making of an allegiance, in: Journal of Historical Sociology 7 (1994) 1-24.

96 Mayke de Jong, Ecclesia and the Frankish policy. Some suggestions for further discussion, in: Staat im frühen Mittelalter, ed. Stuart Airlie/Walter Pohl/Helmut Reimitz (Forschungen zur Geschichte des Mittelalters 11, Wien 2006) 113-132; siehe auch ihren Beitrag in diesem Band. 
che Gemeinschaft bestimmten Populus und von der Gens, die gemeinsame Herkunft und gemeinsames Schicksal auszeichnen. Dadurch veränderte sich der Gens-Begriff; er behielt im Frühmittelalter zwar seine semantische Konnotation der Herkunft, nahm aber durch seine Verknüpfung mit politischem Handeln und christlicher Königsherrschaft Bedeutungen des populus-Begriffes an. Diese Verbindung bereitete letztlich die begrifflichen und affektiven Grundlagen der modernen Nation vor. Uns ist sie deshalb selbstverständlich; sie ist aber keineswegs in allen politischen Systemen anzutreffen. In der Soziologie, der Ethnologie und der Geschichtsforschung ist viel diskutiert worden, ob „Nationen modern sind“ ${ }^{97}$ Terminologisch ist es vermutlich sinnvoll, den Begriff Nation auf die Moderne zu beschränken, während man Ethnizität in den meisten Kulturen finden kann. Was sich jedoch zwischen ihnen sehr unterscheidet, ist die unterschiedliche politische Rolle und Bedeutung ethnischer Zugehörigkeiten. Die These dieses Aufsatzes ist, dass zwischen römischer Antike und lateinischem Mittelalter ethnische Identitäten zu einer wesentlichen Ressource politischer Integration wurden; und dass christliche Diskurse dazu beigetragen haben.

Diese ,ethnische Wende' bereitete grundlegende kognitive und politische Ressourcen der modernen Nation vor; doch führt keineswegs eine lineare Entwicklung von den Regna zur modernen Nation, weder in Einzelfällen noch typologisch. Die ethnische Fundierung überregionaler Herrschaft (ich würde durchaus von ethnischen ,Staaten' sprechen) war zunächst prekär und blieb es lange Zeit auch. In den Regna konnte es dazu sehr unterschiedliche Positionen geben. Etwa war, wie Helmut Reimitz herausgearbeitet hat, für Gregor von Tours die politische Rolle der gens Francorum zwar selbstverständlich, aber kein großes Thema, während Fredegar sie überall hervorhob (und in seiner GregorEpitome jeweils einfügte). ${ }^{98}$ Ein Höhepunkt in der Betonung der politischen Rolle der Franken, aber auch anderer Völker liegt in der frühen Karolingerzeit. Die Herrschaft der Völker war aber auch politisch prekär; die meisten Gentes der ersten Welle haben sich nicht behauptet. In Spanien und später auch in Italien scheiterte mit den Niederlagen der Westgoten und Langobarden das Modell des ethnischen Regnum überhaupt. Auf der anderen Seite führte gerade der Erfolg der Franken und ihrer christlichen Stilisierung zu einer Überdehnung fränkischer Identität, die seit dem 10. Jahrhundert viel von ihrer Bindewirkung einbüßte. Durch die Rolle des Imperiums wurden die Völker zwar nicht verdrängt, aber ihre politische Rolle eingeschränkt. Dafür entstanden seit dem 10. Jahrhundert, nicht zuletzt nach fränkischem Vorbild, eine Reihe neuer Regna der Ungarn, Dänen, Norweger, Schweden, Polen etc., die ebenfalls nach dem ethnisch-christlichen Muster aufgebaut waren, aber nicht aus der Herrschaft einer kleinen Minderheit vorwiegend fremder Herkunft entstanden sind. Trotz aller Wechselfälle hatte das Modell ethnischer Regna großes Potential, sodass etwa die Identitätsressourcen des regnum Burgundionum oder Langobardorum nach deren Untergang immer wieder aufgegriffen wurden. Der moderne Nationalismus hat sich vielfach der frühmittelalterlichen Anfänge bedient. ${ }^{99}$

Das Verhältnis von Regnum und Gens erlaubte wohl gerade durch seine Offenheit und einen gewissen Grad an Ambiguität, durchaus unterschiedliche Ansprüche an die politische Ordnung und die

${ }^{97}$ Anthony D. Smith, The Ethnic Origins of Nations (London 1986) bes. 6-20; Ernest Gellner, Nations and Nationalism (Oxford 1988); ders., The Nation in History. Historiographical Debates about Ethnicity and Nationalism (Hanover 2000); Thomas H. Eriksen, Ethnicity and Nationalism: Anthropological Perspectives (London 1993); Adrian Hastings, The Construction of Nationhood. Ethnicity, Religion and Nationalism (Cambridge 1997).

${ }^{98}$ Helmut Reimitz, Omnes Franci. Identifications and identities of the early medieval Franks, in: Franks, Northmen, and Slavs: Identities and State Formation in Early Medieval Europe, ed. Ildar Garipzanov/Patrick J. Geary/Przemysław Urbańczyk (Turnhout 2008) 51-70.

${ }^{99}$ Dazu ist in den letzten Jahren eine ganze Reihe wichtiger Studien entstanden. Siehe u. a. Die historische Meistererzählung. Deutungslinien der deutschen Nationalgeschichte, ed. Konrad Jarausch/Martin Sabrow (Göttingen 2002); Alfred P. Smyth, The emergence of English identity, 700-1000, in: Medieval Europeans. Studies in Ethnic Identity and National Perspectives in Medieval Europe, ed. id. (Basingstoke/New York 2002) 24-52; Claude Nicolet, La fabrique d'une nation. La France entre Rome et les Germains (Paris 2003); Mythen Europas. Schlüsselfiguren der Imagination. Mittelalter, ed. Inge Milfull/Michael Neumann (Regensburg 2004); Il Medioevo al passato e al presente, ed. Enrico Castelnuovo/Giuseppe Sergi (Arte e storia nel Medioevo 4, Torino 2004); Meistererzählungen vom Mittelalter, ed. Frank Rexroth (Historische Zeitschrift, Beiheft 46, München 2007); The Uses and Abuses of the Past, ed. Jörg Jarnut (Paderborn, im Druck); Ian N. Wood, The use and abuse of the early Middle Ages (1750-2000), in: The Making of the Middle Ages: the Liverpool Lectures, ed. Marios Costambeys/Andrew Hamer/Martin Heale (Liverpool, im Druck); Vergangenheit und Vergegenwärtigung, ed. Helmut Reimitz/Bernhard Zeller (Forschungen zur Geschichte des Mittelalters 14, Wien 2009). 
Machtverteilung zu formulieren. Die ethnische Identifikation stellte einen flexiblen Rahmen bereit, der je nach Bedarf mit Formen politischer Partizipation gefüllt werden konnte, aber die Privilegien der Machtteilnahme auch zu beschränken erlaubte. Die Vorstellung von der Gens scheint vor allem durch die Balance von Abstraktion und Konkretisierbarkeit attraktiv gewesen zu sein. Die gens Francorum war als Heerzug und Versammlung unmittelbar erfahrbar, in ihrer vornehmen Geschichte und ihren biblischen Parallelen vermittelbar, in der Praxis weitgehend dehnbar und dennoch als abstrakter Ordnungsbegriff haltbar. Damit entstand ein dynamisches Verhältnis zwischen Herrschaftsträgern, ethnischer und christlicher Identifikation sowie politischem Ordnungsrahmen, das für große politische Entwürfe genutzt werden konnte und bei Krisen und Brüchen immer noch ein gewisses Maß an Kontinuität garantierte. Die Ressourcen christlich legitimierter und ethnisch fundierter Herrschaft waren unersetzlich genug, dass manche Regna (etwa das regnum Angliae 1066) sogar ihren eigenen Untergang überlebten. Aus dem hingerichteten „König der Juden“ aber war der König der Könige geworden, um dessen Beistand für die Franken im gesamten Regnum im Kriegsfall gebetet werden sollte, wie es karolingische Kapitularien vorsahen. ${ }^{100}$ Die Vorstellung, eine Gens unter ebenfalls in Regna organisierten Gentes zu sein, mag die Franken im Einzelfall getrogen haben. ${ }^{101}$ Aber vielleicht stellte sie gegenüber dem imperialen Bewusstsein der Römer und Byzantiner einen Fortschritt dar, der Europas relative stabile Staatenvielfalt erst ermöglichte.

\footnotetext{
100 Pohl, Liturgie di guerra.

101 So Fried, Gens und regnum.
} 